\title{
Anthropometry in Ancient China--Based on the Physiognomy Book of Divine Fortuneteller Ma Yi
}

\author{
Bo $\mathrm{SHI}^{1,2^{*}}$, Chao $\mathrm{WU}^{1}$ \\ 1. School of Resources and Safety Engineering, Central South University, Changsha, Hunan, \\ 410083, China \\ 2. School of Foreign Studies, Hunan University of Commerce, Changsha, Hunan, 410205, China \\ shibo_safety@163.com
}

Key words: anthropometry; physiognomy; ancient China

\begin{abstract}
Divine Fortuneteller $\mathrm{Ma} \mathrm{Yi}$, the physiognomy book in ancient China, is abundant with vivid records of morphological description and sketches of ancient Chinese. The chosen content about anthropometry from the book is illustrated and interpreted, along with the analyses of the landmarks of measurement, facial features, face shapes, regional differences of human body in this ancient book. It is found that the landmarks for facial measurement and facial shapes resemble those in modern anthropometry and anthropometry difference of region, age and gender were also mentioned in this ancient book. Especially, the classification of body types and palm prints, based on observation and induction, is more comprehensive and subtle than modern anthropometry.
\end{abstract}

\section{Introduction}

Physiognomy dates back to ancient China during the Warring States period (770-221 BC), and it is still very popular in the folklore of China now. Physiognomy in Ancient China is a kind of core culture for fortune-telling and of expanding connotation, including chirognomy and phrenology besides the study of faces. For a long time, ancient physiognomy in China was only regarded as the superstition, because it linked physical characteristics of human body to certain behavioral traits and destiny, which made the scientific community typically greet it with skepticism. However, total denial of Chinese physiognomy is reasonless. In fact, Chinese physiognomy is of scientific significance from the perspective of anthropometry, as it could demonstrate the anthropometry in ancient China with a lot of specific sketches and the morphologic observation about the physical parts.

Therefore, Divine Fortuneteller Ma Yi, a typical physiognomy book in ancient China, is chosen to acquire the relevant information about ancient anthropometry. This ancient book, written by an extraordinary Taoist named Ma Yi in the Northern Song Dynasty (960-1127 AD) of China, is a popular physiognomy book in China which firstly described the physical features of Chinese systematically by collecting the essence of previous physiognomy. It came down the ages completely with many illustrations of body measurement, which were ever used to illustrate the relationship between physical traits and destiny. Though it is a superstition substantially, this book could disclose the ancient philosophy of life, development and safety, and especially it revealed the scientific methods and achievements of ancient anthropometry. This research aims to analyze and illustrate the typical information in Divine Fortuneteller $\mathrm{Ma} Y \mathrm{Yi}$ to explore its contribution to the study of anthropometry in ancient China from a new perspective.

\section{Methodology in the Anthropometry from Divine Fortune Teller Ma Yi}

Methodology in the anthropometry from Divine Fortune Teller Ma Yi is explored and analyzed from the aspects of measurement scope and the procedure.

\section{Measurement Scope}

The observation range of human body in ancient physiognomy of China expanded gradually with the development of Chinese physiognomy. As a typical book, Divine Fortuneteller Ma Yi 
introduced the observation of the relatively systematic 35 body parts, which almost includes all the observation scope in ancient physiognomy of China. The 35 body parts are respectively head, hair, eyebrow, eyes, ears, nose, teeth, beard, neck, brain, back, breast, abdomen, navel, waist, legs, hands, feet, down, naevus, bone, voice, skin, vigor, speckle, line, scrotum, penis, vulvae, arm, philtrum, occipital, urinate, sideburns, tongue. What's more, the focus of measurement and observation is on the face, and there are 35 measuring points in the face marked as Fig. 1.

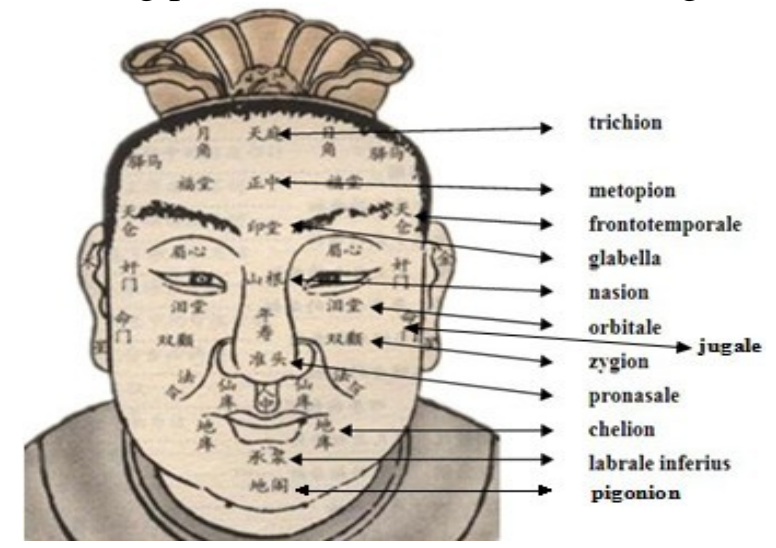

Fig. 1 Landmarks for facial measurement (The arrows and English terms are added by the author.)

\section{Measurement Procedures}

Ancient fortune tellers saw the human body as an organic whole, and summarized some main procedure to do fortune telling. Fortune Teller Ma Yi introduced the procedure: the skeleton and bone are supposed to be observed firstly; then body type should be judged according to the five classifications which would be clarified in detail (Table 1 in Section 3.1 ); then comparatively proportion of trichion-glabella (a), glabella-subnasale (b) and subnasale-pigonion (c) distance (Step 3 in Fig. 2) is analyzed; after observing the proportion of the above three distances, the rough traits are almost obtained, then the specific observing parts like faces and hands are observed carefully and measured seriatim. Such are the procedure from whole to parts to observe and measure the body.

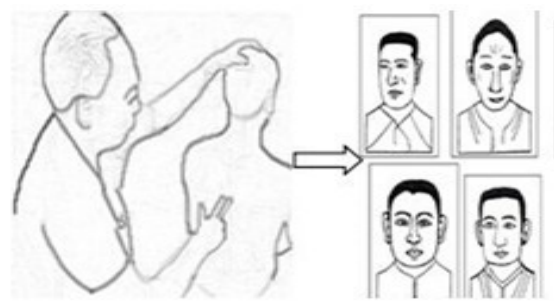

Step 1

Step 2

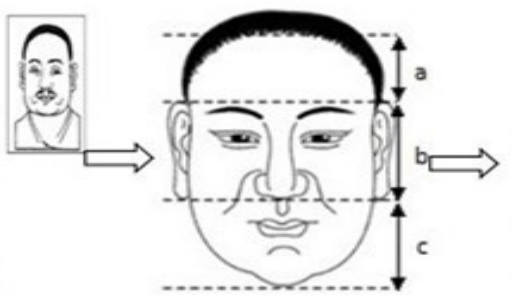

Step 3

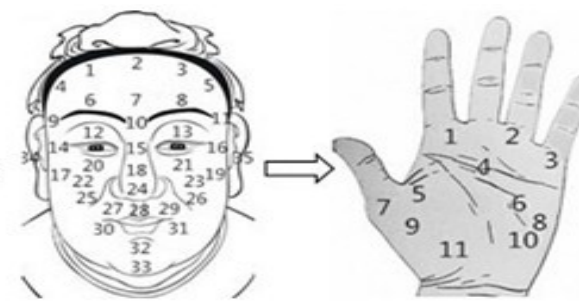

Step 4

Step 5

Step 1: Feeling the bone shape

Step 2: Distinguishing shape types of body and face according to Table 1 and Fig.6

Step 3: Eye-measuring the proportion of trichion-glabella (a), glabella-subnasale (b) and subnasalepigonion (c)

Step 4: Observing 35 measuring points as Fig.1

Step 5: Reading the palmprints and 11 observing positions in hand

Fig.2 Flowchart of Measurement procedures in Divine Fortuneteller Ma Yi 


\section{Ancient Chinese Practices of Anthropometry from Divine Fortuneteller Ma Yi}

Since more portraits with word description and fewer data records were employed in Divine Fortuneteller $\mathrm{Ma} \mathrm{Yi}$, some typical portraits in it were chosen to illustrate its anthropometry information from the whole body to the parts.

\section{Classification of Body Types}

Physiognomy in ancient China is based on the classical Chinese philosophy -- Five Elements theory, which holds that all universal things are composed of five elements --metal, wood, water, fire and soil. Five elements coexist and interplay, which is the existing form of the world and drives the transformation of the world. According to Five Elements theory, Divine Fortuneteller Ma Yi classified the man into five types: metal, wood, water, fire and soil, and their standards of classification are as follows. (Table 1)

Table 1 Five Types of Human Body in Divine Fortuneteller Ma Yi

\begin{tabular}{|c|c|c|c|c|c|c|}
\hline Type & Shape & Limbs & Face & Feature & Complexion & Other \\
\hline Medal & $\begin{array}{c}\text { Thin, straight; } \\
\text { medium height; big } \\
\text { boned }\end{array}$ & $\begin{array}{l}\text { Slender limbs; Small } \\
\text { hands }\end{array}$ & Square & $\begin{array}{l}\text { High brow ridge; } \\
\text { Hollow eyes; } \\
\text { Straight nose }\end{array}$ & White & $\begin{array}{c}\text { Physical } \\
\text { agility; } \\
\text { Ringing sound }\end{array}$ \\
\hline Wood & Slender figure & $\begin{array}{l}\text { Long and thin fingers; } \\
\text { many unorderly palm } \\
\text { prints }\end{array}$ & Long & $\begin{array}{l}\text { Long oral fissure } \\
\text { and thick lips; } \\
\text { prominent } \\
\text { forehead; delicate }\end{array}$ & $\begin{array}{l}\text { Rather } \\
\text { green and } \\
\text { pale }\end{array}$ & $\begin{array}{l}\text { Vigorous; } \\
\text { taciturn }\end{array}$ \\
\hline Water & $\begin{array}{l}\text { Fat and round; } \\
\text { potbelly; narrow } \\
\text { shoulders; long } \\
\text { backbone; flat } \\
\text { buttocks } \\
\end{array}$ & $\begin{array}{l}\text { Tapering fingers; } \\
\text { triangle-shaped palm }\end{array}$ & Round & $\begin{array}{l}\text { Big eyes; shaggy } \\
\text { eyebrow; thick lips }\end{array}$ & Rather black & Costive \\
\hline Fire & $\begin{array}{l}\text { Comparatively small } \\
\text { above the waist; } \\
\text { broad below the } \\
\text { waist }\end{array}$ & $\begin{array}{c}\text { Bony; small hands and } \\
\text { feet }\end{array}$ & Rhombus & $\begin{array}{l}\text { Bushy brows; } \\
\text { straight nose with } \\
\text { exposed nares; } \\
\text { small ears }\end{array}$ & $\begin{array}{l}\text { Rather red, } \\
\text { bronze }\end{array}$ & $\begin{array}{l}\text { Oligotrichosis; } \\
\text { speak fast }\end{array}$ \\
\hline Soil & $\begin{array}{l}\text { Stocky; } \\
\text { rather fat }\end{array}$ & Short neck and fingers & $\begin{array}{l}\text { Big; } \\
\text { round or } \\
\text { square }\end{array}$ & $\begin{array}{l}\text { Big nose; broad } \\
\text { mouth }\end{array}$ & Yellow & $\begin{array}{l}\text { Resonant } \\
\text { voice }\end{array}$ \\
\hline
\end{tabular}

The above classification includes nearly all the body types and gave the details of traits respectively, which some simple methods of summing-up and induction were employed to generate by fortune teller Ma Yi. From the aspects of shape, limbs, face, facial features, complexion, etc, some typical traits were induced to describe five body types.

\section{Face Shape}

Face, the highlight in this ancient book by fortuneteller Ma Yi, was classified and described in a special Chinese style. The shapes of face were expressed in the Chinese pictograph, which is in Chinese pronunciation of YOU(由), JIA（甲）, SHEN（申）, TIAN（田）, TONG（同）, WANG

（王）,YUAN（园）,MU（目）,YONG（用）, FENG（风） respectively from left to right in Fig. 6. Such 10 Chinese characters visually depict 10 different facial forms. YOU(由) was used to describe the face which is of narrow forehead and wide bi-gonial diameter; JIA (甲) was used to describe the face of the wide forehead and pointed jaw; SHEN (申) was used to describe the face of the narrow forehead, wide face breadth and pointed jaw; TIAN (田) was used to describe the square face; TONG (同) refers to the square face of prominent zygion and gotion, WANG (王) refers to the face of prominent frontotemporale, zygion and gotion, YUAN (园) refers to the round and fat face with a big nose, $\mathrm{MU}$ (目) refers to the long face of narrow forehead and bigonial 
diameter, YONG（用） refers to the skew and asymmetric face, FENG（风） refers to the face of prominent frontotemporale and gotion which could be even seen from the backside.

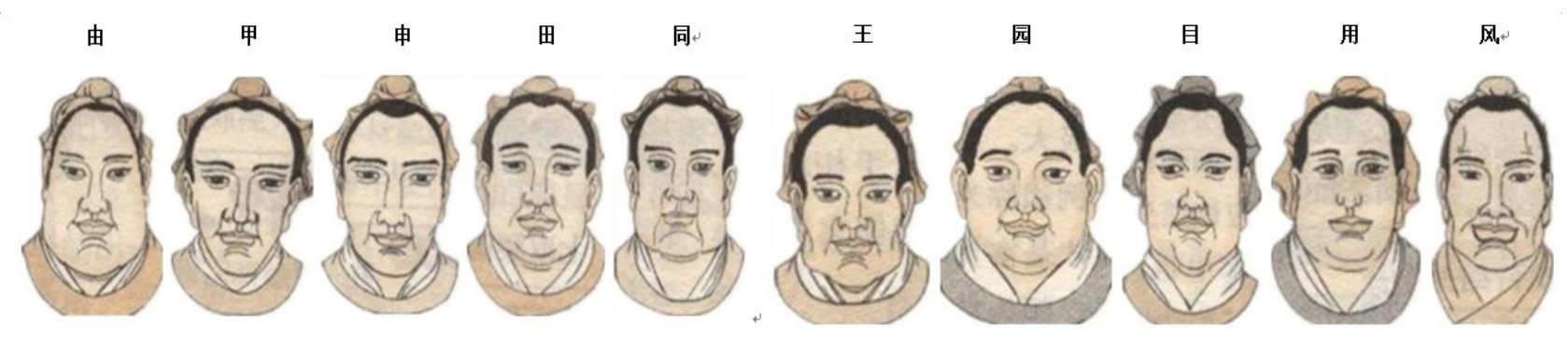

Fig.6 10Types of face shapes

\section{Parts}

In the ancient book of Divine Fortuneteller Ma Yi, facial features, eyebrow, nose, mouth, eyes, ears, were its highlight of description, besides which it also supplied some other parts in details, like philtrum, naevus and palm print. Firstly Eyebrows were classified into 23 types in terms of denseness and sparseness, the inclining angles, continuity. Secondly, eyes were classified into 33 types in terms of the inclining angles, interocular breadth, eye fold of the upper eyelid, opening height of eyeslits, direction of eyeslits. Thirdly, mouths were classified into 16 types in terms of thickness of lips, breadth of the oral fissure, direction of the oral fissure, closure of the lips. Fourthly, noses were classified into 24 types in terms of shapes of nasal tip, nasal profile, nasal root height, breadth of alae nasi. Then, ears were classified into 16 types in terms of auricle abduction, length, breadth, color, lobe types, relative height compared with the position of eyebrow, forms of eternal ears. It also sketched 18 types of philtrum according to linearity, length, breadth and depth, and supplied a face sketch with 46 positions of naevus. What's more, Ma Yi marked out 11 observing spots in the palm and drew 71 types of palm lines in hand.

\section{Variability}

In addition, the variability of anthropometry and observation of human body was found in Divine Fortuneteller $\mathrm{Ma} \mathrm{Yi}$, which indicated the differences of human body in different regions, between male and female, among children, adults and the elderly. To take regional differences in anthropometry in this book for example, the vast territory of China with 56 ethnic groups results in the regional differences in anthropometry. $M a Y i$ pointed out the typical differences of human body in 10 provinces of ancient China. The nomadic people of the northern China were of prominent nasal bone; the people in Huai River Basin were of heavyset and stocky bodily form; the minority in Sichuan Province were of different eye shapes from the Han nationality's; the people inhabiting in Jiangxi Province were of dim complexion; the people inhabiting in Fujian Province mostly had the problem of skeleton hypogenesis; the people in Zhejiang Province were of comely looking; the build of inhabitants in Shandong Proving was tall and straight. Therefore, it is one of redeeming features in Divine Fortuneteller Ma Yi that it realized the regional differences of anthropometry, though some of the mentioned differences were changed a lot over time. When it comes to the observing spots of the body at different ages, Ma Yi pointed that ears were the observing part of a man at the age of 1-14, nose for the age of 40-50, and jaw was the observing part of the man after the age of 60. In addition, this book particularly used a chapter to illustrate the different observation of the female.

\section{Comparison with Modern Anthropometry}

In terms of method, confines, variability and application, comparison between the anthropometry of ancient China based on Divine Fortuneteller Ma Yi and modern anthropometry has revealed the following similarities and differences.

The measurement method is to measure the body directly in ancient anthropometry, similarly, 
this direct method is also frequently used in modern anthropometry in order to acquire data quickly; After measurement and observation of massive materials, the acquired information was summarized and induced, by which the classification was done. Such information processing is also like that in modern anthropometry. Besides, the measure equipments are rulers, L-shaped square and Xinmang copper caliper which resemble some of modern measuring tools and also used today. Based on the above similarities in method and equipment, ancient physiognomy is partly scientific and representative to some extent.

Some observing points marked in the body sketches in Divine Fortune Teller Ma Yi coincide with those in modern anthropometry. For example, 10 facial forms (Fig. 6) are surprisingly the same as R. Pöch Classification (Shao, 1985). 35 landmarks for facial measurement were pointed by $\mathrm{Ma} \mathrm{Yi}$ as shown in Fig. 1, according to which, it is obviously found that some of the facial landmarks, trichion, frontotemporale, orbitale, zygion, labrale inferius, chelion, pronasale, sellion and nasion, coincides with the international landmarks by Martin and Saller (1957).

In this book, most of traits about the body were sketched and described in a static condition; in addition, $\mathrm{Ma} Y i$ indicated the observation in a dynamic condition like modern anthropometry. The motion like the walking posture, eating action and sleeping behaviors were described in the book but without the accurate data report which modern anthropometry can collect.

The book mentioned and illustrated that the observing points and body traits varies with the age, regions and gender, which is well acknowledged in modern anthropometry.

Methods and equipments are limited and imprecise in the ancient time in comparison with the modern anthropometry, so just a few data were noted, not to mention the calculation. Most of the observing information was usually reported by the verbal portraits and painting in Divine Fortune Teller Ma Yi.

Some measuring points and parts were found and classified, like naevus, palm prints and philtrum, which are seldom mentioned or studied in modern anthropometry.

The type of human body is classified into three types: long and thin, medium, short and fat in modern anthropometry, whereas it was classified into five types: metal, wood, water, fire and soil in Divine Fortune Teller Ma Yi. In comparison with the classification of body types in modern anthropometry, physiognomy in ancient China made more subtle and comprehensive distinctions combined with shape, limbs, complexion and sound, etc.

The modern anthropometry is widely applied in many fields, like industry, medicine, national defense, education and fine arts, in the same way the anthropometry in ancient China was ever widely used in traditional Chinese medicine and manufacturing. However, that in Divine Fortune Teller Ma Yi was just confined to predict the fate, by which ancient emperors selected the generals and ministers to consolidate the power and propagandized fatalism to maintain the morale of the people.

\section{Conclusion}

Within the confines of the ancient times, Divine Fortuneteller Ma Yi inevitably mixed the truth of human body with something mysterious and fetishistic. On the other hand, it is of reasonable value that it has kept an accountant of much anthropometry information in ancient China. Based on the longtime observation of Chinese body and the collection of previous works, the description and sketches of human body in Divine Fortuneteller Ma Yi objectively recorded the main morphological characteristics of ancient Chinese based on statistical induction, which helps to the anthropology study of human morphology and heredity. 5 body shapes with comprehensive traits, 10 types of facial shapes, 35 landmarks for facial measurement, 35 body parts and especially 71 palm prints were discovered in the book for demonstration and analysis, and its classification of body parts is useful for reference. In addition, it indicated the regional differences of human body, gender differences and anthropometry of different ages to some extent.

Based on the above research, anthropometric record in ancient physiognomy of China could be typically demonstrated, however, anthropometry in ancient China is actually of much richer content and more extensive domain far beyond the category shown in Divine Fortuneteller Ma Yi. Efforts 
are still necessary for further studies to explore the anthropometry trace in ancient China, which may contribute to determine the role of environment, heredity, aging and racial factors on human body.

\section{References}

[1] Jaruwan Klamklaya, Angoon Sungkhaponga, 2008. Anthropometry of the Southern Thai Population. International Journal of Industrial Ergonomics 38, 111-118

[2] Tan Kay Chuan, Markus Hartono, Naresh Kumar, 2010. Anthropometry of the Singaporean and Indonesian populations. International Journal of Industrial Ergonomics 40, 757-766

[3] Nicolas Marmaras, George Poulakakis, Vasilis Papakostopoulos, 1999, Ergonomic Design in Ancient Greece, Applied Ergonomics 30, 361-368

[4] Deepa R. Mane, 2010. Anthropometric and Anthroposcopic Analysis of Different Shapes of Faces in Group of Indian Population: A pilot Study. Journal of Forensic and Legal Medicine, 421-425

[5] Kewal Krishan, 2008. Estimation of Stature from Cephalo-Facial Anthropometry in North Indian Population. Forensic Science International 181 (2008), 52.e1-52.e6

[6] T.S. Balueva, 2010. A Comparison of the Medieval and Modern Population of the Novgorod Region Based on Facial Reconstruction. Archaeology Ethnology \& Anthropology of Eurasia 38, 135-144

[7] Ziqing Zhuang, 2010. Facial Anthropometric Differences among Gender, Ethnicity, and Age Groups. Occupational Hygiene Society 54, 391-402

[8] Hassin R.,Trope Y., 2000. Facing Faces: Studies on the Cognitive Aspects of Physiognomy, Journal of Personality and Psychology 78, 837-852

[9] Xiangqing Shao, 1985. The Manual of Anthropometry. Shanghai Dictionary Press, China (in Chinese)

[10] Yang Xu, 2010. Divine Fortuneteller Ma Yi, Mandarin Version. Shanxi Normal University Press, China (in Chinese)

[11] Wei Guo, 2009. The Study of Daoist Ma Yi. Culture Research of Wutai Mountain. (in Chinese)

[12] Dongrui Liu, 1981. Criterion of Metrology in Ancient China. Journal of History. 3, 6-12 (in Chinese) 